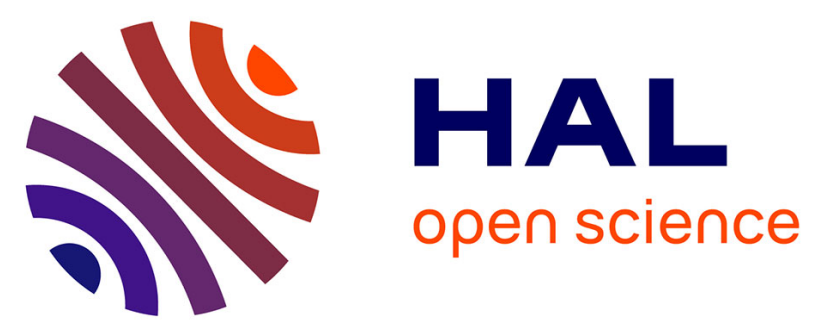

\title{
Capacity for colonization and degradation of horse manure and wheat-straw-based compost by different strains of Agaricus subrufescens during the first two weeks of cultivation
}

Anne Marie Farnet da Silva, Leila Qasemian, Frédérique Peter-Valence, Florence Ruaudel, Jean-Michel Savoie, Elisée Ferré

\section{To cite this version:}

Anne Marie Farnet da Silva, Leila Qasemian, Frédérique Peter-Valence, Florence Ruaudel, JeanMichel Savoie, et al.. Capacity for colonization and degradation of horse manure and wheat-strawbased compost by different strains of Agaricus subrufescens during the first two weeks of cultivation. Bioresource Technology, 2013, 131, pp.266-273. 10.1016/j.biortech.2012.12.141 . hal-02069284

\author{
HAL Id: hal-02069284 \\ https://hal.science/hal-02069284
}

Submitted on 15 Mar 2019

HAL is a multi-disciplinary open access archive for the deposit and dissemination of scientific research documents, whether they are published or not. The documents may come from teaching and research institutions in France or abroad, or from public or private research centers.
L'archive ouverte pluridisciplinaire HAL, est destinée au dépôt et à la diffusion de documents scientifiques de niveau recherche, publiés ou non, émanant des établissements d'enseignement et de recherche français ou étrangers, des laboratoires publics ou privés. 



\title{
Capacity for colonization and degradation of horse manure and wheat-straw-based compost by different strains of Agaricus subrufescens during the first two weeks of cultivation
}

\author{
Anne-Marie Farnet ${ }^{\mathrm{a}, *}$, Leila Qasemian ${ }^{\mathrm{a}}$, Frédérique Peter-Valence ${ }^{\mathrm{a}}$, Florence Ruaudel $^{\mathrm{a}}$, \\ Jean Michel Savoie ${ }^{\mathrm{b}}$, Elisée Ferré ${ }^{\mathrm{a}}$ \\ a Equipe Vulnérabilité des Systèmes Microbiens, IMBE, UMR CNRS IRD 7263, Institut Méditerranéen de Biodiversité et d'Ecologie, Campus de l'Etoile, \\ Aix Marseille Université, 13397 Cedex 20, Marseille, France \\ bINRA, UR1264 MycSA, Mycologie et Sécurité des Aliments, BP 81, F-33883 Villenave d'Ornon, France
}

\section{H I G H L I G H T S}

The Agaricus subrufescens strains studied colonize European standard mushroom compost

- Colonization markers were similar or higher than those obtained for Agaricus bisporus.

- Functional diversity of substrate microorganisms was not altered by the fungal growth.

\begin{abstract}
A B S T R A C T
The potential of Agaricus subrufescens strains to colonize and transform horse manure and wheat-strawbased mushroom compost under the physico-chemical conditions typically used for Agaricus bisporus was assessed. Lignocellulolytic activities, $\mathrm{H}_{2} \mathrm{O}_{2}$ production and substrate transformation (assessed via CP/MAS NMR of ${ }^{13} \mathrm{C}$ ) for certain $A$. subrufescens strains were similar or even greater than those obtained for an A. bisporus strain used as control. Moreover, the functional diversity of the microbial communities of the substrate was not altered by the growth of $A$. subrufescens after 2 weeks. These findings obtained with mesocosms simulating the incubation phase of the mushroom production process hold promise for the improvement of cultivation of this tropical Agaricus species on European standard mushroom compost.
\end{abstract}

\section{Introduction}

Mushroom cultivation is a valuable biotechnological process which produces healthy food while converting a wide range of residues from the agro-industries. Agaricus subrufescens Peck is a cultivated mushroom also known as Agaricus blazei Murill. and Agaricus brasiliensis Wasser, Didukh, Amazonas \& Stamets (Kerrigan, 2005; Wasser, 2011). It was firstly isolated in Brazil in the 1960 s and is widely consumed both in Brazil and in oriental countries such as Japan or China for its nutritional properties (edible mushrooms are known for their high concentrations of vitamins or proteins in the biomass). Moreover, this mushroom is reputed to produce bioactive molecules that prevent or combat diseases such as diabetes and cancer but their physiological roles are still not clear (Oliveira Lima et al., 2011). Despite its economic

\footnotetext{
* Corresponding author. Tel./fax: +3349128 8190.

E-mail address: anne-marie.farnet@imbe.fr (A.-M. Farnet).
}

importance, little information about $A$. subrufescens cultivation is available in the literature. A recent review (Largeteau et al., 2011) has described the data available about its cultivation process. Yet, there is clearly a need to improve methods of cultivation of A. subrufescens in Brazil (currently involving, for instance, long cultivation cycles of 90-120 days from casing) because production levels are very low compared to A. bisporus (Siqueira et al., 2009), the button mushroom commonly cultivated in Europe. Recently, Zied et al. (2011a) estimated the average A. subrufescens production in Brazil at $8-16 \%$ after 120 days of cultivation on substrates made from local wastes, such as coffee pulp or sugar cane bagasse.

Strains used for the cultivation of A. subrufescens in Brazil are marketed as varieties collected indigenously, selected through domestication and adaptation to the cultivation conditions of the farms (type and formulation of the compost and local environmental conditions). The consequences are great variability in production yields, long growth cycles and a lack of control over the specific growth characteristics of the strains. Despite the probable 
tropical origin of the species, several specimens had been isolated in temperate countries (Kerrigan, 2005) and could be a source of new cultivars adapted for cultivation in northern countries with interesting yield potentials (Llarena Hernández et al., 2011; Zied et al., 2011b).The different steps in the process used for $A$. subrufescens cultivation are usually similar to those involved in A. bisporus cultivation. This means that it should be possible to develop efficient cultivation in Europe, where A. bisporus is cultivated on a large scale. However certain conditions such as the cultivation substrate or temperature used in Brazil vary from those found in Europe: sugarcane bagasse-based substrate is one of the most commonly employed, and relatively high temperatures $\left(27^{\circ} \mathrm{C}\right)$ are selected (Zied et al., 2011a). Testing whether European culture conditions used for A. bisporus (wheat-straw-based substrate, temperature, relative humidity, time allowed for growth) are suitable for an efficient cultivation of $A$. subrufescens, and how they can be improved, is of prime importance for the development of the diversification in industry of Agaricus mushroom. Because of the risks of contaminations and development of competitors, the first days following the spawning are critical for the success of the culture, the aim of this work was to assess the capacity of $A$. subrufescens to colonize and transform rapidly horse manure and straw based compost. We thus focused on the preliminary phase of mushroom cultivation i.e. spawn-running during the two first weeks, using analyses of the functional diversity of substrate microbial communities and degradation of lignocelluloses. Mesocosms were used to measure the capacity of different strains of $A$. subrufescens to colonize a wheatstraw-based compost: wild strains of various origins (Brazil and Europe) and cultivars were selected and an A. bisporus strain was used as control for substrate colonization. The substrate colonizing potential of the fungal strains was tested by monitoring (i) both lignocellulolytic activities produced by the different strains and laccase isoform electrophoretic patterns to assess the potential diversity of these enzymes involved in phenolic compound degradation (the recalcitrant fraction of culture substrate), (ii) $\mathrm{H}_{2} \mathrm{O}_{2}$ production, which is known to be correlated to substrate colonization (Savoie et al., 2007), (iii) the chemical transformation of lignocellulosic material using ${ }^{13} \mathrm{C}$ solid-state NMR spectroscopy, (iv) the functional diversity of bacterial communities of the substrates using a catabolic level physiological profile (CLPP).

\section{Methods}

\subsection{The fungal strains}

Six strains of A. subrufescens and one strain of A. bisporus from the Collection of Germplasms of Agaricus in Bordeaux (CGAB), INRA, France, were used. CA 487 is a wild strain of $A$. subrufescens isolated in France in 2006. CA 454 is a subculture of the original strain cultivated for the first time in Brazil in the 1960s and registered as A. blazei ATCC 76739. CA 646 and CA 647 are two cultivars sold in Europe by Mycelia under the reference numbers 7700 and 7703, respectively. CA 560 was isolated in Botucatu, Brazil (1999) from a commercial farm and CA 572 is a Brazilian cultivar purchased by D.C. Zied in 2007. Their original reference numbers are ABL-99/28 and ABL-07/58 respectively, in the Culture Collection of the Edible and Medicinal Mushroom Module of São Paulo State University (UNESP).

The A. bisporus strain Bs527 is a copy of the cultivar 30A (Euromycel) placed in the CGAB in 1997.

\subsection{Mesocosm experimental set-up}

Precultures were performed in glass Petri dishes containing $12 \mathrm{~g}$ dry weight of rye grains (provided by Somycel, Langeais, France) inoculated with 6 plugs $(1 \times 1 \mathrm{~cm})$ of malt agar cultures. These precultures were incubated in a climatic chamber at $25^{\circ} \mathrm{C}$ and $90 \% \mathrm{RH}$ (relative humidity) for 10 days and were used to inoculate the mesocosms. $450 \mathrm{~g}$ of fresh mushroom compost (135 g dry weight) were placed in a $2 \mathrm{~L}$ glass pot in order to obtain a final volume of compost of $20 \times 16 \times 6 \mathrm{~cm}$. They were inoculated with $3 \%(\mathrm{w} / \mathrm{w})$ of rye grains (dry weight), which were thoroughly homogenized with the compost under aseptic conditions. The compost was a commercial compost produced by SARL Renaud et Fils at Avy, France, for the cultivation of $A$. bisporus. The main raw materials used were horse manure and wheat straw, and the phase I of composting was performed indoor. The quality of the compost was assessed by the yields obtained in commercial cultivation facilities that reached standards. Three mesocosms were prepared for each strain and were incubated in a climatic chamber at $25^{\circ} \mathrm{C}$ and $90 \%$ of RH for 15 days in darkness. An un-inoculated control (with the compost alone), UIC, was also prepared and incubated under the same conditions.

\subsection{Microbial catabolic profiles via Biolog EcoPlate ${ }^{\mathrm{TM}}$}

For each mesocosm (three for each strain), one gram of substrate was vigorously shaken in $100 \mathrm{~mL}$ of a sterilized desorption-solution (Sodium pyrophosphate $0.08 \mathrm{~g} / \mathrm{L}$ ) for $1 \mathrm{~h}$ and then brought to a final $\mathrm{OD}=0.001$ at $595 \mathrm{~nm}$. Hundred fifty microlitter of the extracted solution were used to inoculate all 96 wells of a BIOLOG EcoPlate (Biolog, California, USA). One EcoPlate ${ }^{\mathrm{TM}}$ was used for three mesocosm extracts since each 96 -well plate containing three replicates, each with 31 different carbon sources, one per well, and a water blank. The plates were incubated at $25^{\circ} \mathrm{C}$ for $48 \mathrm{~h}$ and the absorbance was read at $490 \mathrm{~nm}$ using a microplate reader (Tecan, France). To measure the functional diversity (FD), the Shannon's diversity index (Shannon and Weaver, 1949) was calculated (Zack et al., 1994) from:

$\mathrm{FD}=-\sum \mathrm{pi}(\ln \mathrm{pi})$, where pi is the ratio of color development of well $i$ to the sum of color development of all positive wells. Microbial activity for each microplate was assessed as average well-color development (AWCD) calculated as follows: $A W C D=\sum O D i / 31$ where ODi is the optical density for each well.

\subsection{Hydrogen peroxide concentration in compost}

To evaluate the mycelial colonization of the substrate, the level of $\mathrm{H}_{2} \mathrm{O}_{2}$ extractable from the compost was quantified as described by Savoie et al. (2007). Briefly, $150 \mathrm{mg}$ of lyophilized substrate milled to powder was added to $4 \mathrm{~mL}$ of phosphate buffer, $0.1 \mathrm{M}$ pH6 and incubated at $30^{\circ} \mathrm{C}$ for $15 \mathrm{~min}$. After centrifugation $(10,000 \mathrm{~g}$ for $4 \mathrm{~min}), 2 \mathrm{~mL}$ of supernatant were placed at $80^{\circ} \mathrm{C}$ for $40 \mathrm{~min}$. Samples were centrifuged $(10,000 \mathrm{~g}$ for $4 \mathrm{~min})$ and $250 \mu \mathrm{L}$ of supernatant was added to $500 \mu \mathrm{L}$ of 3-dimethylaminobenzoic acid, $7.5 \mathrm{mM}, 125 \mu \mathrm{L}$ of 3-methyl benzothiazolinone hydrazine hydrochloride, $0.6 \mathrm{mM}$, and $250 \mu \mathrm{L}$ of peroxidases in phosphate buffer $0.1 \mathrm{M} \mathrm{pH}$ 6. Absorption was measured at $590 \mathrm{~nm}$ and a standard curve was realized with $\mathrm{H}_{2} \mathrm{O}_{2}$ concentrations ranging from 3.1 to $32 \mu \mathrm{M}$.

\subsection{Lignocellulolytic activity assays}

For each mesocosm, enzyme extraction was performed as previously described by Velazquez-Cedeno et al. (2004) using $10 \mathrm{~g}$ of substrate in a $1 \mathrm{~L}$ flask containing $200 \mathrm{~mL}$ of an extraction solution (Polyvinylpolypyrolidone $5.7 \mathrm{~g}, \mathrm{CaCl} 2,0.2 \mathrm{M}$, Tween $80,0.05 \%$ ). These samples were subjected to axial shaking for $1 \mathrm{~h}$ at $120 \mathrm{rpm}$ at room temperature. Solids were eliminated by centrifugation at $10,000 \mathrm{~g}$ for $15 \mathrm{~min}$ and filtration through Whatman GF/D filters $(2.7 \mu \mathrm{m})$ and through Whatman $\mathrm{GF} / \mathrm{C}$ filters $(1.7 \mu \mathrm{m})$. The filtrates 
of each extract were concentrated using polyethyleneglycol to a final volume of $10 \%$ of initial volume.

Laccase activities were measured by monitoring the oxidation of syringaldazine to quinone $\left(\varepsilon^{\mathrm{M}}=65,000 \mathrm{M}^{-1} \mathrm{~cm}^{-1}\right)$ at $525 \mathrm{~nm}$ in acetate buffer, $0.1 \mathrm{M}, \mathrm{pH} 5.4$ on a spectrophotometer Biomate 3 (Fischer Bioblock Scientific). One unit (U) of laccase activity is defined as the amount of $\mu$ moles of quinone of syringaldazine produced per min and per $\mathrm{mL}$ of sample at room temperature. Three assays were performed for each enzyme extract.

CM-cellulase activities were measured with carboxymethylcellulose (CMC) and using a simplified methodology adapted from that of Somogyi-Nelson as described by Farnet et al. (2010). Solution A was composed of $50 \mathrm{~mL}$ of $\mathrm{CuSO}_{4}, 2 \%, \mathrm{Na}_{2} \mathrm{SO}_{4}, 4 \mathrm{~g}$, complemented with $50 \mathrm{~mL}$ of a solution of $\mathrm{Na}_{2} \mathrm{CO}_{3}, 25 \mathrm{~g}, \mathrm{NaHCO}_{3}, 20 \mathrm{~g}$ and sodium potassium tartrate, 25 g, q.s.p. 1 L. Solution B was composed of ammonium-molybdate, $25 \mathrm{~g}, \mathrm{H}_{2} \mathrm{SO}_{4}, 21 \mathrm{ml}$, and $\mathrm{Na}_{2-}$ $\mathrm{HAsO}_{4}, 7 \mathrm{H}_{2} \mathrm{O}, 3 \mathrm{~g}$, q.s.p. $450 \mathrm{~mL}$. To measure CM-cellulase activity, $0.1 \mathrm{~mL}$ of the extract was incubated at $50{ }^{\circ} \mathrm{C}$ for $1 \mathrm{~h}$ in $0.9 \mathrm{~mL}$ of $50 \mathrm{mM}$ acetate buffer (pH 5.0) with $0.1 \% \mathrm{CMC}$. $1 \mathrm{~mL}$ of solution A was added to $1 \mathrm{~mL}$ of the reaction medium and $1 \mathrm{~mL}$ of distilled water; then the mixture was boiled for $20 \mathrm{~min}$ and cooled down in a cold water bath for $15 \mathrm{~min}$. One milliliter of solution $\mathrm{B}$ was added and the mixture was left for $50 \mathrm{~min}$ at room temperature and then centrifuged for $2 \mathrm{~min}$ at $10,000 \mathrm{~g}$. The absorption was measured at $870 \mathrm{~nm}$. Dilutions were performed when necessary. For the calibration curves, $1 \mathrm{~mL}$ of solution A was added to $1 \mathrm{~mL}, 750 \mu \mathrm{L}, 500 \mu \mathrm{L}, 250 \mu \mathrm{L}$ of a solution of glucose $(80 \mathrm{mg} / \mathrm{L})$ q.s. $1 \mathrm{~mL}$. Three assays were performed for each enzyme extract.

\subsection{Laccase isoform patterns on PAGE}

PAGE were performed using 4\% stacking gel and 10\% separating gel at $220 \mathrm{~V}$ with the Mini-Protean III electrophoresis cell (Biorad) in non-denaturing conditions. The protein extracts obtained from the culture substrate were loaded onto the gels. Gel staining was performed using $p$-phenylenediamine at a final concentration of $0.1 \%(\mathrm{v} / \mathrm{v})$ in acetate buffer $0.1 \mathrm{M}, \mathrm{pH} 5.4$ for $30 \mathrm{~min}$. Electrophoresis was performed in triplicate in each case.

2.7. The cross-polarization magic angle spinning ${ }^{13} \mathrm{C}$ nuclear magnetic resonance $\left(C P / M A S{ }^{13} \mathrm{C} N M R\right)$ procedure

CP/MAS ${ }^{13} \mathrm{C}$ NMR spectra were obtained on a Bruker DSX $400 \mathrm{MHz}$ spectrophotometer operating at $100.7 \mathrm{MHz}$. Samples $(600 \mathrm{mg})$ were spun at $10 \mathrm{kHz}$ at the magic angle. Contact times of $2 \mathrm{~ms}$ were applied with a pulse width of $2.8 \mu$ s and a recycle delay of $3 \mathrm{~s}$. Chemical shift values were referenced to glycine signal (carbonyl C at $176.03 \mathrm{ppm}$ ). The ${ }^{13} \mathrm{C}$ NMR spectra were divided into seven chemical-shift regions, according to Ziarelli (2004). Dmfit 2003 software was used to determine the intensity of each chemical-shift-region (Massiot et al., 2002). An index of decomposition (HR\#1 Alkyl-C/O-Alkyl-C) was calculated as described by Baldock et al. (1997). An aromaticity ratio was also calculated to estimate the degree of humification of organic matter and Alkyl-C/COOH-C ratio HR\#2 was used to assess organic matter transformation using the alkyl chain length of organic acids.

\subsection{Statistical analysis}

The significance of differences (enzyme activities, AWCD and $\mathrm{H}^{\prime}$ from Biolog, RMN ratio) between means of three experiments was tested by nonparametric multiple comparison of Kruskal-Wallis. Each experiment was considered as an independent sample. Pearson correlation was tested between enzyme activities and chemical groups defined by ${ }^{13} \mathrm{C}$ NMR and ratios calculated from these data.
The optical absorbances of the 30 wells in the ECO plate were subjected to Principal Component Analysis (PCA) after $48 \mathrm{~h}$ of incubation, considering each substrate as a variable. The intensities of the 22 peaks obtained via $\mathrm{CP} / \mathrm{MAS}$ NMR of ${ }^{13} \mathrm{C}$ analysis of the culture substrate were used for PCA. Statistica Vs 6 (StatSoft, MaisonAlfort, France) was used for statistical analysis and $p$-value $<0.05$ is considered as significant.

\section{Results and discussion}

\subsection{Lignocellulolytic activities, $\mathrm{H}_{2} \mathrm{O}_{2}$ concentration and laccase electrophoretic pattern obtained from culture substrate}

Microbiological and chemical markers of substrate colonization were used to assess the respective potential of six A. subrufescens strains to grow in solid-state fermentation cultures, under conditions used for A. bisporus. Lignocellulolytic activities were determined, since they are involved in the transformation of the main polymers of wheat-straw-based substrates. Previous studies have described factors affecting lignocellulolytic enzyme production in solid-state fermentation, mainly: the nature of nitrogenous sources and of lignocellulosic material, moisture level especially for lignin degradation and, obviously, the fungus under study (Colauto et al., 2010; Elisashvili et al., 2008; Sharma and Arora, 2010). Here, variations in lignocellulolytic activities were potentially due to the diversity of the strains of $A$. subrufescens studied, since all the culture conditions remained constant. The literature suggests that, in mushroom compost before inoculation, no laccase activities are generally observed while cellulases produced by the microflora present at the end of the composting process are often detected. With A. bisporus, it has previously been observed during the incubation phase that laccase activity increased while cellulase activity decreased dramatically with colonization by the mushroom mycelium (Savoie, 1998). Here, we observed that laccase and cellulase activity levels differed depending on the strain considered (Table 1). Three strains of A. subrufescens (CA 572, CA 646 and CA 647 ) produced high laccase activities and weak cellulase activities were observed compared to the other A. subrufescens strains. However, their cellulase activities in the compost were similar to those of $A$. bisporus. Thus, these three strains more recently cultivated, are apparently those with the highest compost colonizing ability as revealed by lignocellulolytic enzymes.

No strong differences in lignocellulolytic activities between $A$. bisporus and most of the $A$. subrufescens strains were observed. However, it is noteworthy that certain A. subrufescens strains (CA 572 and CA 646) produced higher laccase activities than the $A$. bisporus strain. This is interesting since laccases in spent mushroom substrates of $A$. subrufescens cultivated in Brazil have been shown to be of interest for soil bioremediation (Ribas et al., 2009). The high potential for laccase production observed here in a European compost is encouraging, having developmental implications for the environmental sciences. The cultivation substrate might indeed be a source of crude laccases for enzymatic oxidation of phenolic compounds or degradation of aromatic pollutants such as $\mathrm{PAH}$ (polycyclic aromatic hydrocarbons), as proposed for A. bisporus (Trejo-Hernandez et al., 2001). Moreover, in our study, a high diversity of laccase isoforms was observed in compost colonized by A. subrufescens. Laccase electrophoretic patterns of enzyme extracts obtained from the culture substrate showed four bands whatever the A. subrufescens strains considered, whereas only two bands were observed with A. bisporus (data not shown). This result is in accordance with the isoform pattern obtained in liquid culture where the same number of apparent isoforms (four) was observed (data not shown). Ullrich et al. (2005) have purified a laccase from an A. blazei strain from Vietnam and found only one iso- 
Table 1

Laccase activities, Cellulase activities and $\mathrm{H}_{2} \mathrm{O}_{2}$ concentration $(n=3)$ measured in the horse manure- and straw-based compost inoculated with Agaricus bisporus (Bs 527) or six strains of $A$. subrufescens after incubation at $25^{\circ} \mathrm{C}$ for 14 days. AWCD and Shannon Weaver index $\left(\mathrm{H}^{\prime}\right)$, based on Ecoplate data $(n=3)$ after $48 \mathrm{~h}$ of incubation of the microbial extract obtained from the substrate. The letters define the mean values which are statistically different from each other according to multiple comparison of Kruskal-Wallis (Dunn Procedure).

\begin{tabular}{|c|c|c|c|c|c|c|c|}
\hline & \multicolumn{7}{|l|}{ Agaricus strains } \\
\hline & Bs 527 & CA 560 & CA 454 & CA 572 & CA 646 & CA 647 & CA 487 \\
\hline Laccase & $15.79 \pm 2.49 \mathrm{ab}$ & $26.83 \pm 2.90 \mathrm{abc}$ & $24.80 \pm 3.71 \mathrm{abc}$ & $77.99 \pm 7.61 \mathrm{~d}$ & $48.65 \pm 10.41 \mathrm{~cd}$ & $40.96 \pm 4.87 \mathrm{bcd}$ & $13.04 \pm 0.26 \mathrm{a}$ \\
\hline Cellulase & $0.46 \pm 0.10 a b$ & $3.39 \pm 0.83 \mathrm{bc}$ & $5.91 \pm 1.00 \mathrm{c}$ & $0.265 \pm 0.11 \mathrm{a}$ & $0.10 \pm 0.26 \mathrm{a}$ & $0.68 \pm 0.36 a b c$ & $2.50 \pm 0.22 \mathrm{bc}$ \\
\hline $\mathrm{H}_{2} \mathrm{O}_{2}$ concentration & $19.13 \pm 0.81 \mathrm{a}$ & $64.17 \pm 1.92 \mathrm{abcd}$ & $55.28 \pm 1.08 \mathrm{abc}$ & $81.39 \pm 2.74 \mathrm{~cd}$ & $27.23 \pm 1.68 \mathrm{ab}$ & $104.21 \pm 5.65 \mathrm{~d}$ & $78.76 \pm 5.41 \mathrm{bcd}$ \\
\hline AWCD & $0.075 \pm 0.002 \mathrm{ab}$ & $0.025 \pm 0.03 a$ & $0.669 \pm 0.056 \mathrm{abc}$ & $0.887 \pm 0.089 b c$ & $0.930 \pm 0.282 b c$ & $0.019 \pm 0.016 \mathrm{a}$ & $0.594 \pm 0.112 a b c$ \\
\hline $\mathrm{H}^{\prime}$ & $0.87 \pm 0.10 \mathrm{ab}$ & $0.21 \pm 0.21 \mathrm{a}$ & $1.25 \pm 0.14 b c$ & $1.32 \pm 0.04 \mathrm{bc}$ & $1.34 \pm 0.07 c$ & $0.29 \pm 0.32 a$ & $1.27 \pm 0.07 \mathrm{abc}$ \\
\hline
\end{tabular}

form in liquid culture. As stated by Ullrich et al. (2005) little is known about the lignocellulolytic system of this mushroom, thus the laccase diversity of the strains under study here seems to be promising and further investigations about their biochemical properties are needed.

$\mathrm{H}_{2} \mathrm{O}_{2}$ production was also monitored as an indicator of culture substrate colonization, as proposed by Savoie et al. (2007) for $A$. bisporus. This method is used to characterize colonization kinetics of lignocellulosic substrates: $\mathrm{H}_{2} \mathrm{O}_{2}$ measured in compost can be generated either directly by enzymes involved in sugar oxidation or from active oxygen species also produced during substrate transformation. However, though the method has been proved to efficiently discriminate the colonization potential of various white-rot fungi, it seems to be of less value for intraspecies comparisons of substrate colonization potential (Savoie et al., 2007). Here, we found that all the $A$. subrufescens strains had the same level of $\mathrm{H}_{2} \mathrm{O}_{2}$ production: only strain CA 647 exhibited higher $\mathrm{H}_{2} \mathrm{O}_{2}$ production compared to CA 646 and CA 454.

3.2. Catabolic level physiological profile of the microbial communities of the culture substrate

The nature of the cultivation substrate strongly influences the equilibrium of the microbial communities, which can enhance the growth of competing or even pathogenic microorganisms (Colauto et al., 2010). This is why the chemical and microbiological composition of the substrate is of high importance in mushroom cultivation. Whereas there are several studies on microbial communities during the composting phase (Silva et al., 2009; Székely et al., 2009), little is known about how mushroom growth modifies microbial communities in mushroom compost during colonization. Here, the microbial characterisation of the substrate was investigated via functional diversity. Average Well Color Development (AWCD) and Shannon-Weaver index of biodiversity $\left(\mathrm{H}^{\prime}\right)$ were calculated from optical densities obtained and are shown in Table 1. For AWCD, differences were observed between mesophilic bacterial communities of compost inoculated with certain Agaricus spp. strains and those from UIC. Certain microbial populations may have been eliminated from the compost because of the growth of the mushroom mycelium, which would explain a weaker AWCD in mesocosms inoculated with the A. bisporus strain and with strains CA 560 and CA 647 than that of UIC. AWCD was also weaker for substrates inoculated with strains CA 560 and CA 647 compared to those inoculated with strains CA 572 and CA 646. H' varies in the same way as AWCD: the catabolic diversity of the microbial communities of the substrate decreased and differed between (i) substrates inoculated with A. bisporus, strain CA 560, strain CA 647 (0.21 and 0.29 respectively) and UIC (1.36) and (ii) substrates inoculated with CA 560 and 647 (0.21 and 0.29 respectively) and substrate inoculated with CA 572 and CA 646 (1.32 and 1.34 , respectively). These results thus show that, when the substrate is inoculated either with A. bisporus or with A. subrufescens

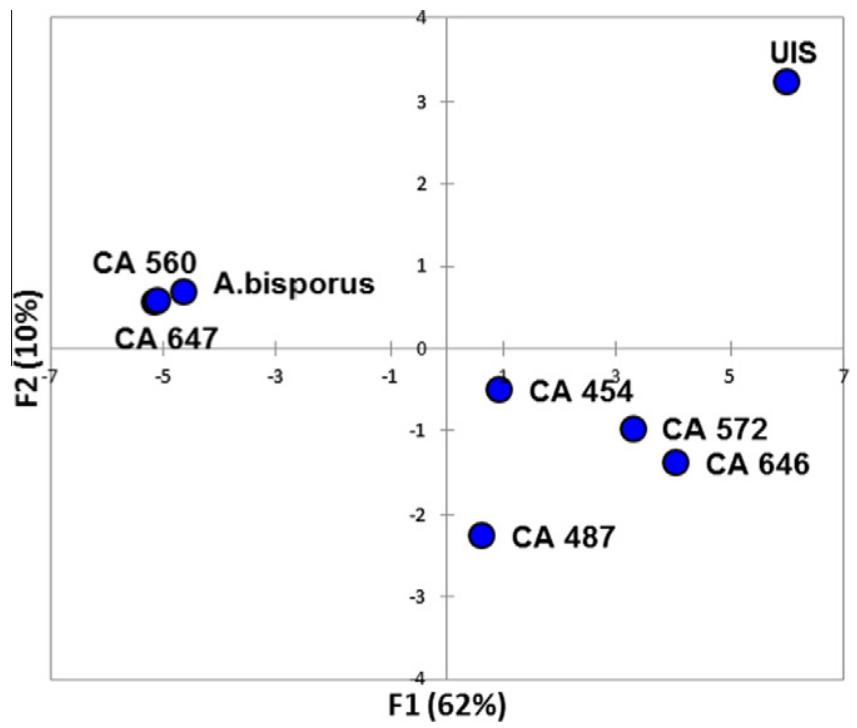

Fig. 1. PCA (based on Pearson corelation) performed using $\mathrm{OD}_{48 \mathrm{~h}}$ of each Ecoplate Carbone source $(n=31)$ as variables. The two first factors (F1 + F2) counted for $72 \%$ of total variance. Catabolic profile of compost microbial communities was obtained for UIS: Un-Inoculated Substrate and compost inoculated with Agaricus bisporus (strain Bs 527) or six strains of A. subrufescens (CA 454, CA 487, CA 560, CA 572, CA 646, CA 647).

strains CA 560 and CA 647, both the catabolic diversity and the global activity (characterized by AWCD) of the microbial communities of the compost are affected. The growth of these Agaricus strains may have altered the equilibrium of the microbial communities of the compost, leading to a shift in biodiversity. Cai et al. (2009) found a change in the microbial diversity of casing soil when using Phospholipid fatty acid (PLFA) as markers, depending on the stage of $A$. bisporus development. However, here $\mathrm{H}^{\prime}$ and AWCD did not change for A. subrufescens strains CA 454, CA 487, CA 572 and CA 646 compared to UIC. Thus, our results suggest that for most of the A. subrufescens strains studied (4 out of 6 ) the diversity of the mesophilic microbial communities of the compost is maintained during the two first weeks of colonization. This is of major importance, since these communities are known to contribute to the electivity of the substrate. Previous findings have indeed demonstrated the major role played by the microbial communities of mushroom substrates in preventing antagonist contamination (Velazquez-Cedeno et al., 2008). Moreover, the microbial communities of substrate used for mushroom cultivation can modify nutrient allocation, and microenvironmental conditions in substrate are known to strongly influence mushroom growth (Carabajal et al., 2012).

PCA was also performed from Ecoplate data and results are shown in Fig. 1 (F1 and F2 explain 72\% of variance). Projections 


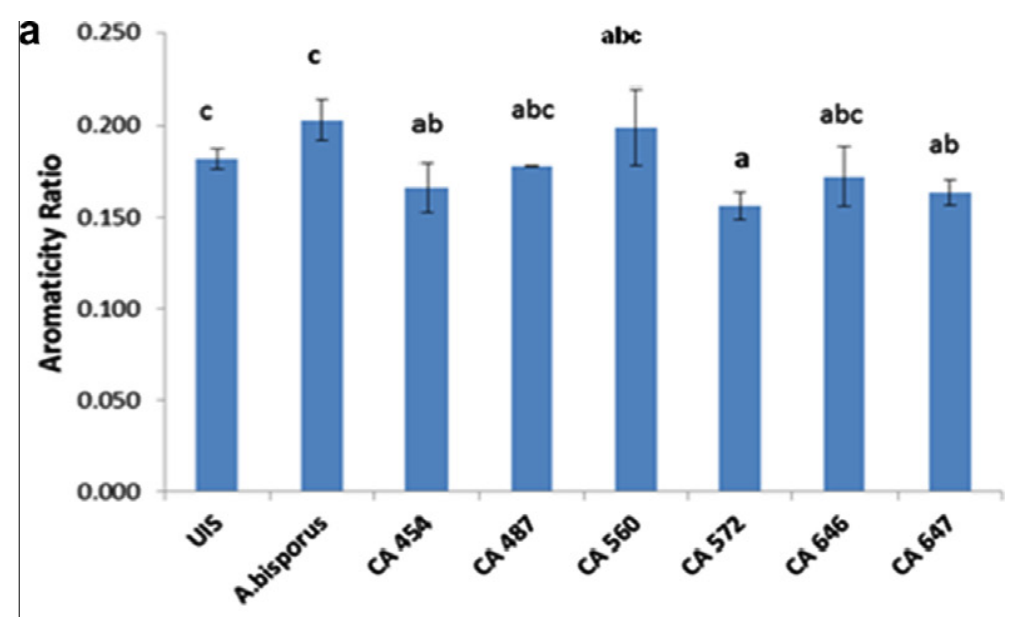

b

(HR\#1)
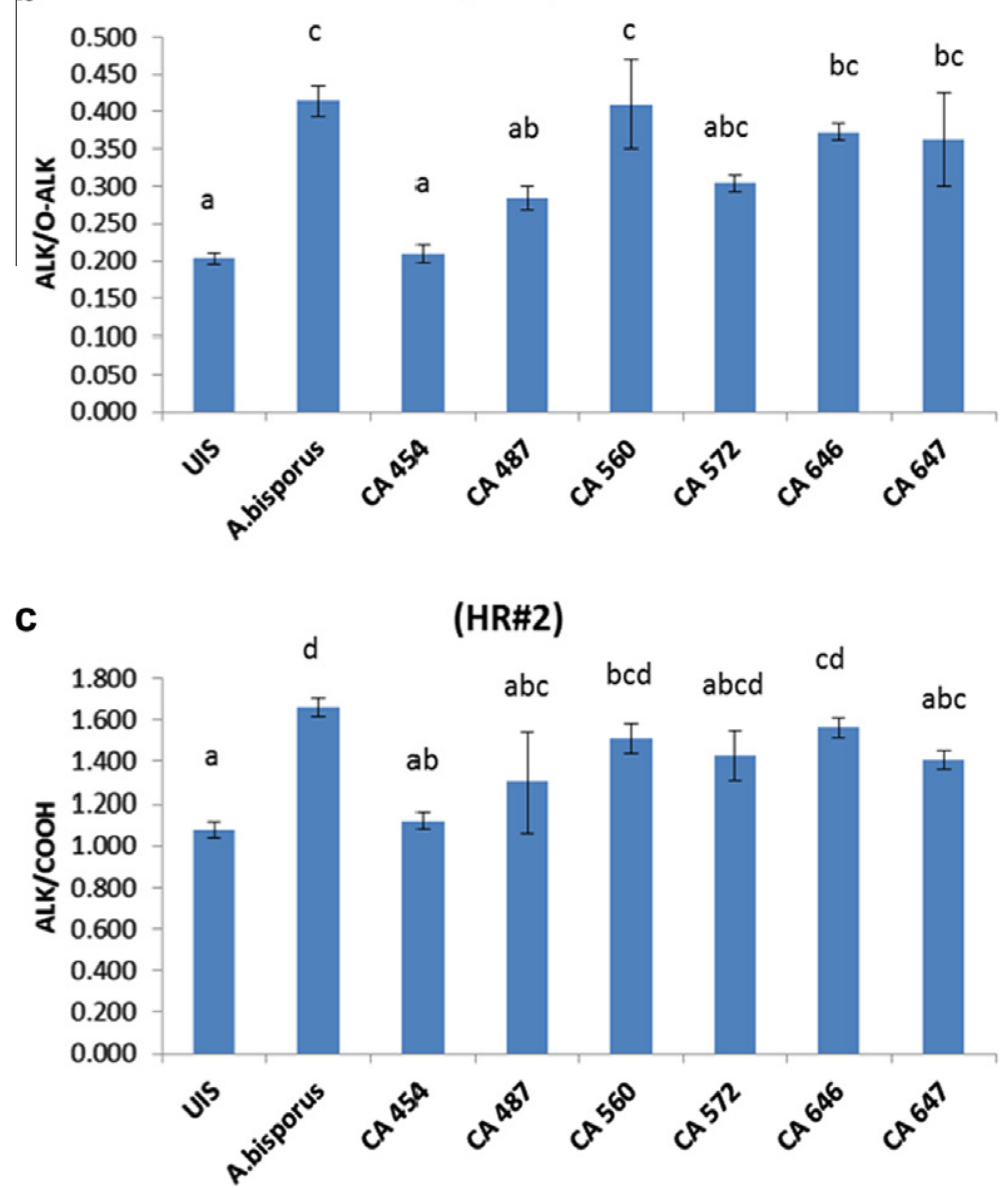

Fig. 2. Aromaticity ratio and two humification ratios, HR\#1, Alkyl-C/O-Alkyl-C and HR\#2, Alkyl-C/COOH-C, calculated from the relative intensities of chemical functions from ${ }^{13} \mathrm{C}$ NMR data from Un-Inoculated Substrate (UIS) and horse manure and straw-based compost inoculated with six different Agaricus subrufescens strains (CA 454, CA 487, CA 560, CA 572, CA 646, CA 647) and A. bisporus, after incubation at $25^{\circ} \mathrm{C}$ for 14 days. The different letters indicate when values differ significantly according to Kruskal-Wallis test and Dunn procedure for multiple comparisons of means $(p<0.05)$.

of both the A. bisporus strain and A. subrufescens strains CA 560 and CA 647 are clearly separated from UIC and the other A. subrufescens strains according to F1 (62\% of the variance), which corroborates our previous results obtained with $\mathrm{H}^{\prime}$ and AWCD. PCA also shows that strains CA 454, CA 487, CA 572 and CA 646 are differentiated from the control according to $\mathrm{F} 2$ (10\% of variance). This supplementary result indicates that the catabolic structures of the substrate microbial communities differ from those of the control when substrate is inoculated with these A. subrufescens strains. In this case, though functional diversity did not decrease, as shown by $\mathrm{H}^{\prime}$ index (Table 1 ), it may have been altered as a result of fungal inoculation and growth. This result is in accordance with Wang et al. (2011) who also found modifications in the structure of microbial communities (involved in cellulose degradation or nitrogen cycle) in compost inoculated with Penicillium expansum. The two first weeks of compost colonization by the mycelium of $A$. subrufescens and $A$. bisporus modified the equilibrium of the microbial communities of the compost with either a decrease or a shift in 

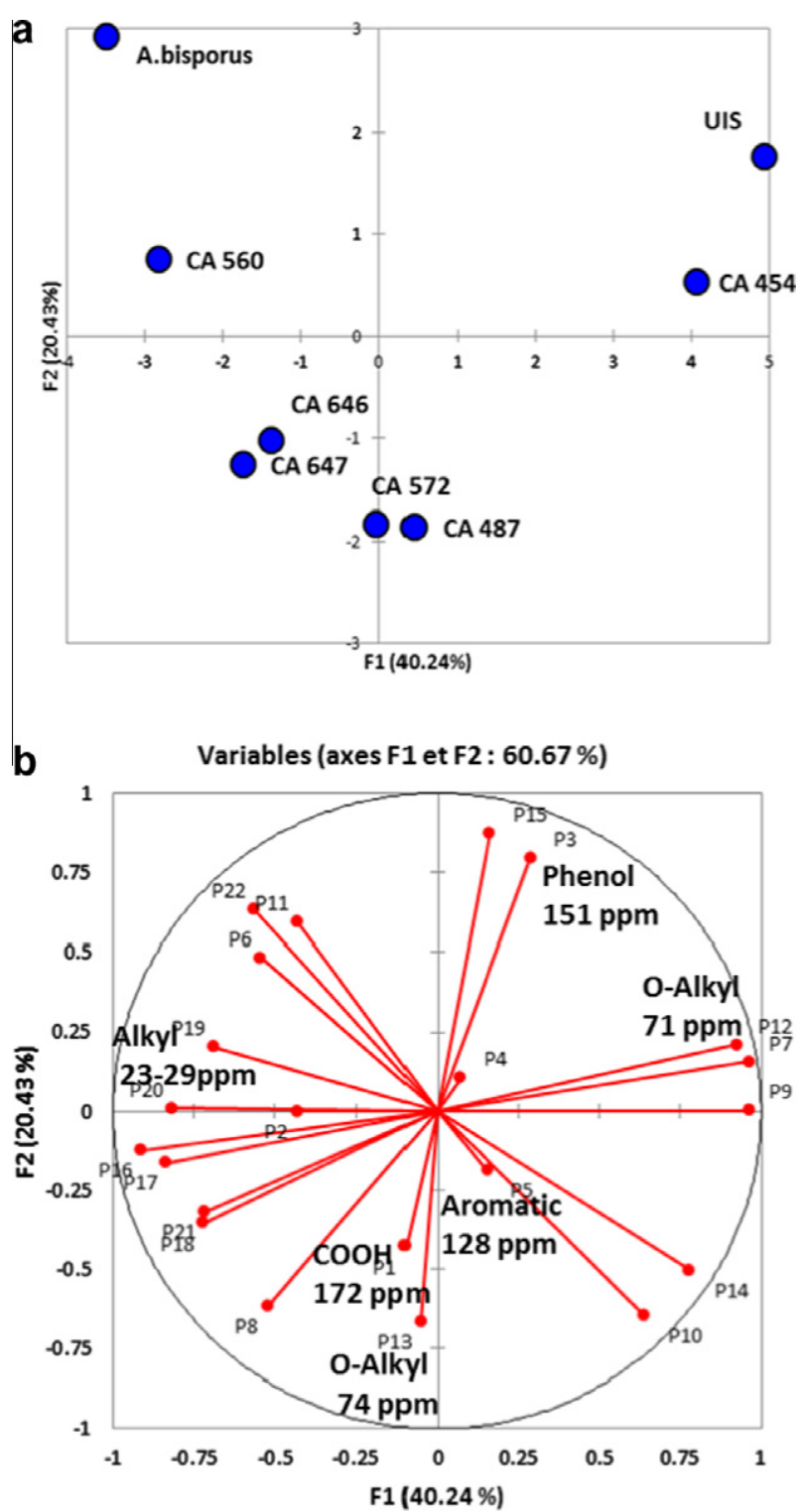

Fig. 3. $\mathrm{PCA}$ (based on Pearson correlation) performed using ${ }^{13} \mathrm{C}$ NMR peaks ( $n=22$, P1-P2, COOH-C, P3-P6, Aromatic-C, P7-P16, O-Alkyl-C, P17-P22, Alkyl-C, ranging from 0 to $200 \mathrm{ppm}$ ) measured in horse manure and straw based compost samples as variables. The two first factors (F1 + F2) counted for $60 \%$ of total variance. The compost samples are: Un-inoculated substrate (UIS), compost inoculated with Agaricus bisporus (strain Bs 527) or with A. subrufescens CA 454, CA 487, CA 560, CA 572, CA 646, CA 647 and incubated at $25{ }^{\circ} \mathrm{C}$ for 14 days.

functional diversity. This is in agreement with the proposed explanation of the decrease in cellulase activities due to changes in microbial communities with colonization by the mycelium.

\subsection{Compost transformation assessed via CP/MAS NMR of ${ }^{13} \mathrm{C}$}

An aromaticity ratio and two humification ratios HR1 (Alkyl-C/ O-Alkyl-C) and HR2 (Alkyl-C/COOH-C) were calculated to assess degradation of culture substrate (Fig. 2a, b and c). The aromaticity ratio significantly decreased for substrates inoculated with strains CA 454, CA 572 and CA 647 compared to that inoculated with A. bisporus and UIC, showing that the aromatic compounds were more efficiently transformed with these three $A$. subrufescens strains. Thus, concerning these strains (CA 454, CA 572 and CA 647), this result differs from those obtained by González Matute et al. (2010) who found that lignin was actively transformed after fruiting body production only. HR1 significantly increased compared to UIC for composts inoculated with the A. bisporus strain and strains CA 560, CA 646 and CA 647. The same result was found for HR2, except for substrate with strain CA 647. The HR2 increase (Alkyl-C/COOH-C) may be explained by a higher amount of fungal biomass production characterized by lipids (Lundberg et al., 2001). Here both HR1 and the aromaticity ratio prove reliable as chemical indicators of organic matter transformation and our results show that the culture substrate was transformed to the same extent both with the A. bisporus strain and with certain A. subrufescens strains. However, for HR1, no correlations were found with either lignocellulolytic activities or $\mathrm{H}_{2} \mathrm{O}_{2}$ production, as explained in the next paragraph.

PCA based on the 22 NMR peaks is shown in Fig. 3a and b (F1 and F2 explain more than $60 \%$ of the variance). While the chemical characteristics of the substrate inoculated differ from control according to F1 (except for strain CA 454), the chemical characteristics of substrate inoculated with $A$. bisporus strain is clearly discriminated from those inoculated with the A. subrufescens strains according to $\mathrm{F} 2$ (20\% of variance). It is also noteworthy that strain CA 454 (expected to be a copy of the original strain from which the cultivation of $A$. subrufescens was developed) and strain CA 560 (one of the oldest cultivars in Brazil) were separated from the other strains. As shown in Fig. 3b, control and CA 454 were separated from the other strains by a negative correlation with C-Alkyl peaks (P17, P19 and P20) and a positive correlation with C-OAlkyl (P12, $74 \mathrm{ppm})$. A bisporus was separated from the A. subrufescens strains (except CA 454) by a negative correlation with Aromatic-C (P5, $128 \mathrm{ppm}), \mathrm{C}-\mathrm{COOH}$ (P1, $172 \mathrm{ppm}$ ) and C-OAlkyl (P13, $71 \mathrm{ppm}$ ) and a positive correlation with C-Phenol (P3, $151 \mathrm{ppm})$. These differences in degradation patterns between old and new cultivars might be the result of a selection by mushroom growers based on visual estimations of compost colonization. For these chemical parameters as for the microbial markers, the European wild isolate CA 487 was grouped with the cultivars of Brazilian origin (CA 646, CA 647 and CA 572), indicating its potential as a new cultivated strain. The lignocellulosic material used in the cultivation substrate is of major importance to obtain acceptable yields of mushroom production. As stated by Royse and Chapula (2009), the substrate is the main expense in mushroom production and it is of great importance to identify substrates with high productivity,

Table 2

Correlation coefficients ( $r$ values) between ${ }^{13} \mathrm{C}$ NMR data, presented here as chemical groups and ratios, and $\mathrm{H}_{2} \mathrm{O}_{2}$ concentration, laccase and cellulase activities. Significant correlations are marked bold with ${ }^{*} p<0.05,{ }^{* *} p<0.01$ and ${ }^{* * *} p<0.001$.

\begin{tabular}{|c|c|c|c|}
\hline & Laccase activities & Cellulase activities & $\mathrm{H}_{2} \mathrm{O}_{2}$ concentration \\
\hline Aromaticity ratio & $-0.52^{* *}$ & 0.07 & $-0.48^{*}$ \\
\hline Humification ratio \#1 (Alkyl C/O-Alkyl C) & 0.25 & -0.27 & 0.12 \\
\hline Humification ratio \#2 (Alkyl C/COOH C) & 0.32 & -0.34 & 0.05 \\
\hline $\mathrm{COOH} \mathrm{C}$ & 0.26 & -0.16 & 0.25 \\
\hline Aromatic C & $-\mathbf{0 . 4 8}^{*}$ & 0.04 & $-\mathbf{0 . 6 0} 0^{* *}$ \\
\hline O-Alkyl C & -0.06 & 0.17 & -0.19 \\
\hline Alkyl C & 0.37 & -0.34 & 0.14 \\
\hline
\end{tabular}


which needs an effective colonization by the mycelium. Various materials have been tested as substrate for A.subrufescens: González Matute et al. (2010) examined the biological efficiency (BE) obtained with substrates based on sunflower seed hull and wheat straw and found BE ranging from 30 to $40 \%$. Wang et al. (2010) used asparagus straw complemented with either cottonseed hull or cow manure and found that BE was higher (44\%) when both lignocellulosic materials were combined. However, these results, compared to those obtained with A. bisporus -for instance, Sanchez and Royse (2009) found a BE of $99.3 \%$ - indicate that investigations to improve A. subrufescens cultivation are still needed and of crucial importance.

\subsection{Correlation between microbial activities and chemical characteristics of the substrate in mesocosms}

Pearson's correlations between chemical characteristics $\left({ }^{13} \mathrm{C}\right.$ NMR signals) and microbial activities (cellulases, laccases and $\mathrm{H}_{2} \mathrm{O}_{2}$ production) are shown in Table 2 . A very significant negative correlation was found between laccase activities and aromaticity ratio $(p<0.01)$. As a corollary, laccase activities were negatively correlated with aromatic-C signal $(p<0.05)$. This negative correlation can be explained by the fact that these enzyme activities are involved in the degradation of recalcitrant fractions of organic matter from plants. Laccases are thus actively involved in these changes in aromaticity ratio. Both the aromaticity ratio and the aromatic-C signal are also negatively correlated with $\mathrm{H}_{2} \mathrm{O}_{2}$ concentration ( $p<0.05$ and $p<0.01$, respectively), showing that $\mathrm{H}_{2} \mathrm{O}_{2}$ concentration used as an indicator of substrate colonization can also be considered as an indicator of substrate degradation and transformation of aromatic compounds, as hypothesized by Savoie et al. (2007). On the other hand, no significant correlations were observed with cellulase activities confirming that $\mathrm{H}_{2} \mathrm{O}_{2}$ concentration does not vary in the same way as these activities, as previously stated by Savoie et al. (2007).

\section{Conclusions}

This study showed that the capacity for colonization and degradation of horse manure and wheat-straw-based compost by different strains of $A$. subrufescens during the first two weeks of culture was strain dependent, but globally as efficient as that of the button mushroom. Strains produced higher laccase activities with four isoforms and this biodiversity could be used for biotechnological purposes. Significant changes in ${ }^{13} \mathrm{C}$ NMR aromaticity signal ratios correlated with laccase activities showing the efficient transformation of compost. Our results also suggest that a European wild isolate and the cultivars currently used appeared to be more efficient than the older strains. They will be used to improve the culture of this medicinal mushroom.

\section{Acknowledgements}

We thank Diego Cunha Zied for purchasing Brazilian A. subrufescens strains and Mrs Marjorie Sweetko for English language revision. This work was supported by the French ANR, project ANR09-BLAN-0391.

\section{References}

Baldock, J.A., Oades, J.M., Nelson, P.N., Skene, T.M., Golchin, A., Clarke, P., 1997. Assessing the extent of decomposition of natural organic materials using solidstate C-13 NMR spectroscopy. Aust. J. Soil Res. 49, 1061-1083.

Cai, W.M., Yao, H.Y., Feng, W.L., Jin, Q.L., Liu, Y.Y., Li, N.Y., Zheng, Z., 2009. Microbial community structure of casing soil during mushroom growth. Pedosphere 19 , 446-452.

Carabajal, M., Levin, L., Albertó, E., Lechner, B., 2012. Effect of co-cultivation of two Pleurotus species on lignocellulolytic enzyme production and mushroom fructification. Int. Biodeter. Biodegr. 66, 71-76.
Colauto, N.B., Reis da Silveira, A., Ferreira da Eira, A., Linde, G.A., 2010. Alternative to peat for Agaricus brasiliensis yield. Bioresour. Technol. 101, 712-716.

Elisashvili, V., Penninckx, M., Kachlishvili, E., Tsiklauri, N., Metreveli, E., Kharziani, T., Kvesitadze, G., 2008. Lentinus edodes and Pleurotus species lignocellulolytic enzymes activity in submerged and solid-state fermentation of lignocellulosic wastes of different composition. Bioresour. Technol. 99, 457-462.

Farnet, A.M. Qasemian, L. Guiral, D., Ferré, E. 2010. A modified method based on arsenomolybdate complex to quantify cellulase activities: application to litters. Pedobiologia 53, 159-160.

González Matute, R., Figlas, D., Curvetto, N., 2010. Sunflower seed hull based compost for Agaricus blazei Murrill cultivation. Int. Biodeter. Biodegr. 64, 742747.

Kerrigan, R.W., 2005. Agaricus subrufescens, a cultivated edible and medicinal mushroom, and its synonyms. Mycologia 97, 12-24.

Largeteau, M.L., Llarena-Hernandez, R.C., Regnault-Roger, C., Savoie, J.-M., 2011. The medicinal Agaricus mushroom cultivated in Brazil: biology, cultivation and nonmedicinal valorisation. Appl. Microbiol. Biotechnol. 92, 897-907.

Llarena Hernández, R.C., Largeteau,M., Farnet, A.-M., Minvielle N., Regnault-Roger C., Savoie J.M., 2011. Phenotypic variability in cultivars and wild strains of Agaricus brasiliensis and Agaricus subrufescens. In: Savoie, J.M., Foulongne-Oriol, M., Largeteau, M., Barroso, G. (Eds.), Proceedings of the Seventh International Conference on Mushroom Biology and Mushroom Products, vol. 2, pp 38-49. Available from: <http://www.wsmbmp.org/Previous_Conference_7.html>.

Lundberg, P., Ekblad, A., Nilsson, M., 2001. ${ }^{13} \mathrm{C}$ NMR spectroscopy studies of forest soil microbial activity: glucose uptake and fatty acid biosynthesis. Soil Biol. Biochem. 33, 621-632.

Massiot, D., Fayon, F., Capron, M., King, I., Le Calve, S., Alonso, B., Durand, J.O., Bujoli, B., Gan, Z.H., Hoatson, G., 2002. Modelling one- and two-dimensional solid-state NMR spectra. Magn. Reson. Chem. 40, 70-76.

Oliveira Lima, C.U.J. de Almeida Cordova, C.O. de Toledo Nobrega, O, Funghetto, S.S., de Oliveira, Gomas, Karnikowski, M., 2011. Does the Agaricus blazei Murill mushroom have properties that affect the immune system? An integrative review. J. Med. Food 14, 2-8.

Ribas, L.C.C., de Mendonca, M.M., Camelini, C.M., Soares, C.H.L., 2009. Use of spent mushroom substrates from Agaricus subrufescens (syn. A. blazei, A. brasiliensis) and Lentinula edodes productions in the enrichment of a soil-based potting media for lettuce (Lactuca sativa) cultivation: Growth promotion and soil bioremediation. Bioresour. Technol. 100, 4750-4757.

Royse, D., Chapula, W., 2009. Effects of spawn, supplement and phase II compost additions ans time of re-casing second break compost on mushroom (Agaricus bisporus) yield and biological efficiency. Bioresour. Technol. 100, 5277-5282.

Sanchez, J.E., Royse, D.J., 2009. Scytalidium thermophilum-colonized grain, corncobs and chopped wheat straw substrates for the production of Agaricus bisporus. Bioresour. Technol. 100, 1670-1674.

Savoie, J.-M., 1998. Changes in enzyme activities during early growth of the edible mushroom, Agaricus bisporus, in compost. Mycol. Res. 102, 1113-1118.

Savoie, J.-M., Salmones, D., Mata, G., 2007. Hydrogen peroxide concentration measured in cultivation substrates during growth and fruiting of mushrooms, Agaricus bisporus and Pleurotus spp.. J. Sci. Food Agric. 87, 1337-1344.

Shannon, C.E., Weaver, T., 1949. A mathematical theory for communication. Bell Syst. Technol. J. 27, 379-423 (and 623-656).

Sharma, R.K., Arora, D.S., 2010. Production of lignocellulolytic enzymes and enhancement of in vitro digestibility during solid state fermentation of wheat straw by Phlebia floridensis. Bioresour. Technol. 101, 9248-9253.

Silva, C.F., Azevedo, R.S., Braga, C., Silva, R., Dias, E.S., Schwan, R.F., 2009. Microbial diversity in a bagasse-based compost prepared for the production of Agaricus brasiliensis. Bras. J. Microbiol. 40, 590-600.

Siqueira, F.G., Dias, E.S., Silva, R., Martosi, E.T., Rinker, D.L., 2009. Cultivation of Agaricus blazei ss. Heinemann using different soils as source of casing materials. Sci. Agric. 66, 827-830.

Székely, A.J., Sipos, R., Berta, B., Vajna, B., Hajdú, C., Márialigeti, K., 2009. DGGE and TRFLP analysis of bacterial succession during mushroom compost production and sequence-aided T-RFLP Profile of mature compost. Microb. Ecol. 57, 522-533.

Trejo-Hernandez, M.R., Lopez-Munguia, A., Ramirez, R.Q., 2001. Residual compost of Agaricus bisporus as a source of crude laccase for enzymic oxidation of phenolic compounds. Process Biochem. 36, 635-639.

Ullrich, R., Huong, L.M., Dung, N.L., Hofrichter, M., 2005. Laccase from the medicinal mushroom Agaricus blazei: production, purification and characterisation. Appl. Microbiol. Biotechnol. 67, 357-363.

Velazquez-Cedeno, M.A., Farnet, A.M., Ferré, E., Savoie, J.M., 2004. Variations in lignocellulosic activities in dual cultures of Pleurotus ostreatus and Trichoderma longibrachiatum on non-sterilized wheat straw. Mycologia 96, 712-719.

Velazquez-Cedeno, M., Farnet, A.M., Mata, G., Savoie, J.-M., 2008. Role of Bacillus spp. in antagonism between Pleurotus ostreatus and Trichoderma harzianum in heat-treated wheat-straw substrates. Bioresour. Technol. 99, 6966-6973.

Wang, H.-Y., Fan, B.-Q., Hu, Q.-X., Yin, Z.-W., 2011. Effect of inoculation with Penicillium expansum on the microbial community and maturity of compost. Bioresour. Technol. 102, 11189-11193.

Wang, Q., Li, B.B., Li, H., Han, J.R., 2010. Yield, dry matter and polysaccharides content of the mushroom Agaricus blazei produced on asparagus straw substrate. Sci. Hortic. 125, 16-18.

Wasser, S.P., 2011. Current findings, future trends, and unsolved problems in studies of medicinal mushrooms. Appl. Microbiol. Biotechnol. 89, 1323-1332.

Zack, J.C., Willig, M.R., Moorhead, D., Howard, L., Wildman, G., 1994. Functional diversity of microbial communities: a quantitative approach. Soil Biol. Biochem. 26, 1101-1108. 
Ziarelli, F., 2004. Applications et développements des méthodes de résonance magnétique nucléaire haute résolution à l'état solide pour les matériaux organiques et inorganiques. Thèse de Doctorat. Université Aix-Marseille I (p. 110).

Zied, D.C., Minhoni, M.T.A., Kopytowski-Filho, J., Barbosa, L., Andrade, M.C.N., 2011a. Medicinal mushroom growth as affected by non-axenic casing soil. Pedosphere $21,146-153$.
Zied, D.C., Pardo-Gimenez, A., Savoie, J.-M., Pardo-Gonzalez, J.R., Callac, P., 2011b. Indoor method of composting and genetic breeding of the strains to improve yield and quality of the almond mushroom Agaricus subrufescens. In: Savoie, J.M., Foulongne-Oriol, M., Largeteau, M., Barroso, G. (Eds.), Proceedings of the Seventh International Conference on Mushroom Biology and Mushroom Products, vol. 1, pp. 424-432. Available from: <http://www.wsmbmp.org/ Previous_Conference_7.html>. 